\title{
Time Required to Protect the Intestinal Tract of Chicks against Salmonella enterica serovar Enteritidis using Competitive Exclusion
}

\section{Author(s)}

Sterzo EV

Paiva JB

Penha Filho RAC

Berchieri Junior A

Departamento de Patologia Veterinária da Faculdade de Ciências Agrárias e Veterinárias de Jaboticabal (FCAV-Unesp).

\section{ABSTRACT}

Competitive exclusion (CE) has been designed to accelerate the colonization of the alimentary tract of young commercial birds and it has been also used to repopulate the digestive tract after antibiotic therapy. The method has been successfully adopted as a means to prevent enteric salmonellosis. The present study was carried out to evaluate if CE is able to prevent this kind of infection. Newly hatched chicks were given a CE culture and at different intervals of time birds infected with Salmonella Enteritidis were placed together with the group of treated birds. CE culture was prepared from feces of adult laying hens incubated overnight at 37C under aerobic conditions. Birds were killed 4 and 8 days after challenge and viable counts of Salmonella Enteritidis were assessed in the cecal contents. The results showed that Salmonella infection was reduced even if CE culture administration was concomitant with the inclusion of the infected bird in the group.

\section{INTRODUCTION}

Newly hatched free-range birds hatch and live together with their parents. This contact allows that microorganisms excreted by the parents colonize the gut of young birds. The acquired intestinal microbiota helps the birds to grow up healthy and acts as a defense mechanism against harmful microorganisms. The processes of installation of microorganisms in the intestinal tract and gut colonization last up to six weeks (Spencer \& Garcia, 1995). In the modern poultry industry, birds are hatched in artificial incubators, which are submitted to a rigorous process of cleaning and disinfection. Thus, chicks hatch in a sterile ambient and have no contact with the parents. There will be a delay in the formation of the gut microflora. Furthermore, vertically transmitted infectious pathogens like Salmonella Enteritidis (Lister, 1988) reach the alimentary tract before the microflora is even mature. Nurmi \& Rantala (1973) prepared a culture of feces of adult birds and administered it to newly hatched broiler chicks; the procedure was successful to protect against Salmonella Infantis infection. The so-called "Nurmi concept" or "Competitive Exclusion (CE)" has been adopted in Sweden since 1981 as part of the national program to control Salmonella infection (Wierup et al., 1992). The detection of Salmonella in broilers has decreased to lower than $1 \%$ in carcasses, feces and in the environment since then (Wierup et al., 1992). CE is recommended worldwide by several researchers (Corrier et al., 1994; Rambousek et al., 1995; Mead, 2000; Davies \& Breslin, 2003).

The control of Salmonella in commercial poultry has become a matter of concern since outbreaks of human Salmonellosis caused by Salmonella Enteritidis (SE) were reported worldwide and the main source of infection in the outbreaks were meat and eggs of chickens 
Sterzo EV, Paiva JB, Penha Filho RAC, Berchieri Junior A
Time Required to Protect the Intestinal Tract of Chicks against Salmonella enterica serovar Enteritidis using Competitive Exclusion
(Rodrigue et al., 1990; Barrow, 2000). The adoption of $\mathrm{CE}$ is one of the measures suggested to prevent SE dissemination among birds (Mead, 2000). CE cultures should be given to newly hatched chicks as soon as possible, since SE acquired through vertical transmission will spread out easily among the birds in the beginning of life (Soncini et al., 2000; Oliveira et al., 2000). After feeding procedures are started, 48 hours are necessary for the intestinal flora to be established. This period might be reduced to 2 hours when the birds are treated with CE culture, although complete colonization might last up to 32 hours (Soerjadi et al., 1981). Starvic (1985) considers that protection is adequate within 6 hours. $C E$ was effective in preventing contact infection when the culture was administered to newly hatched chickens 24 hours before challenge (Oliveira et al., 2000). However, protection might be obtained earlier according to Almeida et al. (2002). In view of the lack of information, in ovo administration of CE culture has been tried as a means to accelerate the installation of the intestinal microflora. However, the procedure was unsuccessful, since the product was deleterious to the embryo (Meijerhof \& Hulet, 1997). Therefore, this study was carried out in order to assess the period of time needed to protect chicks against SE. Newly hatched chicks were given a broth culture of feces of adult birds orally and were then challenged with SE, by introducing an infected bird in each group of birds at different intervals of time after CE treatment.

\section{MATERIALS AND METHODS}

\section{Bacteria}

It was used a spontaneous mutant of $S$. Enteritidis phage type 4 resistant to both nalidixic acid and spectinomycin (SE nal/specr). Cultures were prepared in nutrient broth (Oxoid CM67) and incubated overnight using a shaking water bath (100 strokes $/ \mathrm{min})$ at $37^{\circ} \mathrm{C}$.

\section{Competitive Exclusion culture}

Fresh feces were obtained from adults birds reared in the poultry facilities of Faculdade de Ciências Agrárias e Veterinárias (FCAV-UNESP) and inoculated in nutrient broth $(1: 10 \mathrm{w} / \mathrm{v})$. The culture was incubated aerobically at $37^{\circ} \mathrm{C}$ for 24 hours, without shaking and then tested for the absence of Salmonella.

\section{Birds}

Newly hatched chicks were obtained from a commercial broiler hatchery. Groups of six birds were housed together in a box separated from other groups.
Feed with no additives and drinking water were provided ad libitum. A heat source was provided. Swabs from the cloacae were assessed for the absence of Salmonella.

\section{Experimental Procedure}

Birds in groups 1, 2, 3 and 4 were given $0.1 \mathrm{~mL}$ of the fecal culture (CE) orally. Birds in group 5 did not receive CE culture (control group). At 0, 6, 12 and 24 hours after $C E$ treatment, birds were challenged, i.e., two birds infected with SE were placed with each group. There were four replicates per group (Table 1).

\begin{tabular}{|c|c|c|c|}
\hline Groups & Replicates & Treatment & Challenge (Hours) \\
\hline 1 & 4 & CE & 0 \\
\hline 2 & 4 & CE & 6 \\
\hline 3 & 4 & CE & 12 \\
\hline 4 & 4 & CE & 24 \\
\hline 5 & 4 & - & 0 \\
\hline
\end{tabular}

Number of birds per replicate $=6 ; C E=$ Competitive Exclusion.

Infected birds had been inoculated with $0.1 \mathrm{~mL}$ broth culture of SENal'Spec' containing $1.2 \times 10^{5} \mathrm{CFU}$.

Three and five days after the challenge, three birds from each group and one infected bird were sacrificed to assess the viable counts of SENal'Spec' in the cecal contents.

\section{Bacterial counting}

Decimal dilutions of cecal contents were made in PBS, pH 7.4 and $0.1 \mathrm{~mL}$ aliquots were cultured on Brilliant Green agar containing nalidixic acid $(100 \mu \mathrm{g} /$ $\mathrm{mL})$ and spectinomycin $(100 \mu \mathrm{g} / \mathrm{mL})$. Plates were incubated at $42^{\circ} \mathrm{C}$ for 24 hours.

\section{RESULTS AND DISCUSSION}

The modern practices in the poultry industry use artificial incubation and hatching. The colonization of the enteric tract of newly hatched chicks by desirable microorganisms is delayed compared to chicks hatched in contact with adult birds. Therefore, the alimentary tract can be easily colonized by pathogenic bacteria (Fowler \& Mead, 1989). Under natural conditions, microorganisms that are first established usually remain for the rest of the life in the alimentary tract of the birds (Savage, 1987; Miles, 1993). Therefore, gut colonization in the beginning of life would promote a natural barrier impeding the colonization and multiplication of Salmonella and other pathogenic bacteria in the alimentary tract (Fowler \& Mead, 1989; Oliveira et al., 2000). 
The risk of Salmonella infection in young birds is still high even if a Competitive Exclusion product is administered. Some serotypes, like Salmonella Enteritidis, can be transmitted vertically (Gast, 1997; Berchieri Jr., 2000) and spread rapidly among young birds afterwards (Soncini et al., 2000; Oliveira et al., 2000). Despite having contact with birds infected with Salmonella, other birds might be protected by CE techniques. According to Oliveira et al., 2000), colonization of the intestinal tract is fast in CE techniques and help to prevent infection by contact among young birds. Besides, there are indications that the desired effect can be achieved even after infection, as reported by Ziprin et al., (1993) in birds treated 72 hours after experimental infection with Salmonella Typhimurium. Thus, the concept of Nurmi has been recommended worldwide as part of Salmonella control programs in birds (Day, 1992), although it is still not clear how long it takes to effectively protect teh birds. Therefore, this work was carried out to assess the protection of newly hatched chicks in contact with birds infected with Salmonella Enteritidis. This design was chosen because chicks infected with Salmonella Enteritidis have been reported as the main source of infection to poultry flocks (Zancan et al., 2000; Gama et al., 2003).

All the birds in the control group were rapidly infected, showing that the dissemination occurs almost immediately in the beginning of life, as previously shown by Soncini et al., (2000) and Oliveira et al., (2000). Viable counts of SE in the cecal contents of control birds were high (Table 2). Conversely, most birds from the treated groups showed no SE counts and some birds had quite few organisms. These data corroborate previous studies that reported beneficial effects of CE given to birds at the same time of the challenge with Salmonella or after it (Ziprin et al., 1993). Protection has been reported as early as two hours (Soerjadi et al., 1981) and at six hours (Starvic 1985) after treatment. However, in the present study, protection was adequate even if treatment and challenge were performed simultaneously $(p<0.05)$. Similar findings have been reported by Almeida et al., (2002) using a similar approach.

In conclusion, according to the experimental conditions used in this study, CE culture may prevent Salmonella Enteritidis infection through contact between young birds just after its administration.

\begin{tabular}{|c|c|c|}
\hline \multirow[t]{2}{*}{ Groups } & \multicolumn{2}{|c|}{$\begin{array}{l}\text { Viable number of SE Nal Spec }\left(\log _{10}\right) \\
\text { per gram of cecal contents }\end{array}$} \\
\hline & 4 days post contact & 8 days post contact \\
\hline 1 & $<2(<2-<2)$ & $2.53(<2-3.89)$ \\
\hline 2 & $2.34(<2-3.52)$ & $<2(<2-<2)$ \\
\hline 3 & $<2(<2-<2)$ & $<2(<2-<2)$ \\
\hline 4 & $2.52(<2-4.31)$ & $<2(<2-<2)$ \\
\hline 5 & $4.92(2.22-7.62)$ & $5.55(3.15-7.95)$ \\
\hline
\end{tabular}

$<2=\log _{10}$ median count per gram from 24 birds (range in parenthesis).

\section{REFERENCES}

Almeida WAF, Berchieri Jr A, Barrow PA. The effect of serial culture and storage on the proactive potential of a competitive exclusion preparation. Revista Brasileira de Ciência Avícola 2002; 4:163-167.

Barrow PA. The paratyphoid Salmonellae. Review Science Technology 2000; 19:351-375.

Berchieri Jr A. Salmoneloses aviárias. In: Berchieri Jr A, Macari M, editor. Doenças das aves. Campinas. FACTA; 2000. p. 185-195.

Corrier DE, Hollister AG, Nisbet, DJ. Competitive exclusion of Salmonella Enteritidis in leghorn chicks: comparison of treatment by crop gavage, drinking water, spray or lyophilized alginate beads. Avian Disease 1994; 38:297-303.

Davies RH, Breslin MF. Observations on the distribution and persistence of Salmonella enterica serovar enteritidis phage type 29 on a cage layer farm before and after the use of competitive exclusion treatment. British Poultry Science 2003; 44:551-7.

Day C. Competitive exclusion in poultry - a review. Spring Lane North: Life- Care Products, 1992. p.2-18.

Fowler NG, Mead GC. Competitive exclusion and Salmonella in poultry. Veterinary Record 1989; 11. P.512.

Gama NMSQ, Berchieri Jr A, Fernandes SA. Occurrence of Salmonella sp in laying hens. Revista Brasileira de Ciência Avícola 2003; 5:1521.

Gast RK. Salmonella infections. In: Calnek BW et al. Diseases of poultry. $10^{\circ}$ ed. Ames: lowa State University Press; 1997. p. 81121.

Lister SA. Salmonella enteritidis infection in broilers and broiler breeders Veterinary Record 1988; 123:350.

Mead GC. Prospects for "competitive exclusion" treatment to control Salmonellas and other food borne pathogens in poultry. The Veterinary Journal 2000; 159:11-123.

Meijerhof R, Hulet RM. In ovo injection of competitive exclusion culture broiler hatching eggs. Journal of Applied Poultry Research 1997; 6:260-266. 
Miles RD. Manipulation of the microflora of the gastrointestinal tract: natural ways to prevent colonization by pathogens. In: ALTECH BIOTECNOLOGY in THE FEED INDUSTRY, 1993, Florida. Proceedings... p.133-50.

Nurmi E, Rantala M. New aspects of Salmonella infection in broiler production. Nature 1973; 241:210-1.

Oliveira GH, Berchieri Jr A, Barrow PA. Prevention of Salmonella infection by contact using intestinal flora of adults birds and/or a mixture of organic acids. Brazilian Journal of Microbiology 2000; 31:116-120.

Rambousek MJ, Iba AM, Stachissini AV, Berchieri Jr A. The effect of carbohydrate administration on experimental infection with Salmonella serotypes in chickens. Revista de Microbiologia 1995; 26:32-36.

Rodrigue DC, Tauxe RV, Rowe B. International increase in Salmonella enteritidis. a new pandemic? Epidemiology and infection 1990; 105:21-7.

Savage DC. Factors influencing biocontrol of bacterial pathogens in the intestine. Food Technology 1987; 41:82-87.

Soerjadi AS. Some measurements of protection against paratyphoid Salmonella and Escherichia coliby competitive exclusion in chickens. Avian Diseases 1981; 25:706-12.

Soncini RA, Mores MAS, Costa JLA. Transmissão horizontal de Salmonella Enteritidis em pintos de um dia. Revista Brasileira de Ciência Avícola 2000; 2:94.

Spencer JL, Garcia MM. Resistence of chicksand poults fed vermicompost to ceacal colonization by Salmonella. Avian Pathology 1995; 24:157-70.

Starvic S. Competitive exclusion of Salmonella from newly hatched chicks by mixtures of pure bacterial cultures isolated from fecal and cecal contents of adults birds. Journal of Food Protection 1985; 48: 778-82

Wierup RW, Wahltrow H, Engstrom B. Experience of 10 years of exclusion treatment as a part of the Salmonella control programme in Sweden. International Journal food Microbiology 1992; 15(3/4): 287-91.

Zancan FT, Berchieri Jr A, Fernandes SA. Salmonella spp investigation in transport boxes of day-old birds. Brazilian Journal of Microbiology 2000; 31:229-232.

Ziprin RL, Corrier DE, DeLoach JR. Control of established Salmonella typhimurium intestinal colonization with in vivo-passaged anaerobes. Avian Diseases 1993; 34(3):183-188. 